Kalpa Publications in Civil Engineering
Volume 1, 2017, Pages 157-162
ICRISET2017. International Conference on Re-
search and Innovations in Science, Engineering
\&Technology. Selected papers in Civil Engineering $\quad \mathrm{KaLpo}$

\title{
Unit Quantity Contract as a Mitigation of Unbalanced Bidding
}

\author{
Rohitkumar R. Prajapati ${ }^{1}$ \\ Student, M. Tech Construction Engineering Management, BVM Engineering College, Vallabh \\ Vidyanagar, Gujarat, India ${ }^{1}$ Email ID: rohitprajapati2401@gmail.com \\ Prof. J. J. Bhavsar ${ }^{2}$ \\ Associate Professor, Civil Engineering Department, BVM Engineering College, Vallabh Vidyanagar, \\ Gujarat, India ${ }^{2}$ Email ID: jjbhavsar@bvmengineering.ac.in \\ Abstract - Government construction sector is having major issue in Item Rate Contract - \\ Unbalance bidding. Projects bid by Contractors at very low rate like Building projects 15-30\% \\ below than SOR rates. Road projects having much lower rates compare to Building projects. \\ Government SOR rates are higher than the actual rate is not the reason behind that. Its \\ contractor's strategy to make bid amount as low as possible by making tender Unbalance. \\ Unbalanced tender affects the healthy competition between contractors as well almost removes \\ the genuine bidders. If the strategy of contractors turned positive than they may earned fat profit, \\ which puts burden on the government. On the other hand, they may suffer from loss. Avoidance \\ of loss may affect the quality of the work and enhances corruption. To avoid the loss of \\ government, bad quality of work and corruption this topic is chosen to find the alternative to \\ mitigate the unbalance tender.
}

Keywords—Unbalance Bidding; India; Mitigation;

\section{INTRODUCTION}

There are four different approaches to make tender unbalance.

1. Front-end loading

In the front loaded tender, contractors quote too high rates in the items which are going to be executed early. So they can get enough money in the initial payments and they can use the same money for the rest of the work.

2. Back-end loading

In this contractors quote the higher rate in the items which are going to be executed late to take the advantage of price escalation.

3. Quantity Error exploitation 
This is the most important approach for making tender unbalance. In the same contractor quotes higher rates in some items which expected to exceed than the estimated quantities. And inversely, lower rates in items which expected to decrease compared to estimated quantities.

4. Collusive bid unbalancing

When an officer from employer side colludes with bidder and provides him or her confidential information about the tender items which are subject to a change after the award of contract. So that bidder manipulates the rate of such items and get a chance to remain lowest without compromising the profit.

This seems as a normal thing but it is very important to get the award of contract. And now-a-days this practice is most widely used to crack the contract battle by keeping desired profit.

Government department (Roads and Buildings department, Gujarat) has also faced many problems due to unbalance rates and they have also introduced clause to mitigate front end loading.

ONE HYPOTHETICAL EXAMPLE TO UNDERSTAND THE ISSUE OF UNBALANCE TENDER.

\begin{tabular}{|c|c|c|c|c|c|c|c|c|c|}
\hline Item & Quantity & SOR rate & Estimated cost & Contractor-1 & Total & Contractor-2 & Total & Contractor-3 & Total \\
\hline Brick work & 10 & 3000 & 30,000 & 3500 & 35,000 & 2300 & 23,000 & 2800 & 28,000 \\
\hline Plast & 100 & 150 & 15,000 & 55 & 5,500 & 185 & 18,500 & 140 & 14,000 \\
\hline Total & & & 45,000 & & 40,500 & & 41,500 & & 42,000 \\
\hline
\end{tabular}

Tender Percentage below: $\{(40,500 \times 100) \div 45,500\}-100=-10 \%$

AS PER THE R\&B TENDER DOCUMENTS' CLAUSE - 1A

Permissible limits for Brick work item for not being unbalance:

$$
\begin{aligned}
& 3000-10 \%=2700 \\
& 2700+10 \%=2970 \text { (Max.) } \\
& 2700-10 \%=2430 \text { (Min.) }
\end{aligned}
$$

Permissible limits for Plaster item for not being unbalance:

$$
\begin{gathered}
150-10 \%=135 \\
135+10 \%=148.5 \text { (Max.) } \\
135-10 \%=121.5 \text { (Min.) }
\end{gathered}
$$

From the list of bidder Contractor 1 found Lowest (L1) bidder. But from the above calculation we found that Contractor 1 and Contractor 2 has quoted unbalance rates. Though the Contractor 3 is the genuine bidder he won't awarded the contract.

Contractor 1 would have thought that item 1 Brick masonry is expected to increase than the estimated quantity. So he had quoted higher rates in the same item and lower rates in other item. Contractor 2 would have thought that item 2 Plaster work is expected to increase than the estimated quantity. So he had quoted higher rates in the same item and lower rates in other item. By doing same practice contractor make the tender as low as possible.

Following are the few actual examples of Quantity Error Exploitation from the data gathered from the contractors to cost much. Tender is having such items like the disposing earth. Contractors uses that items to manage profit and minimizing tender amount and by doing so they make the tender unbalance. 


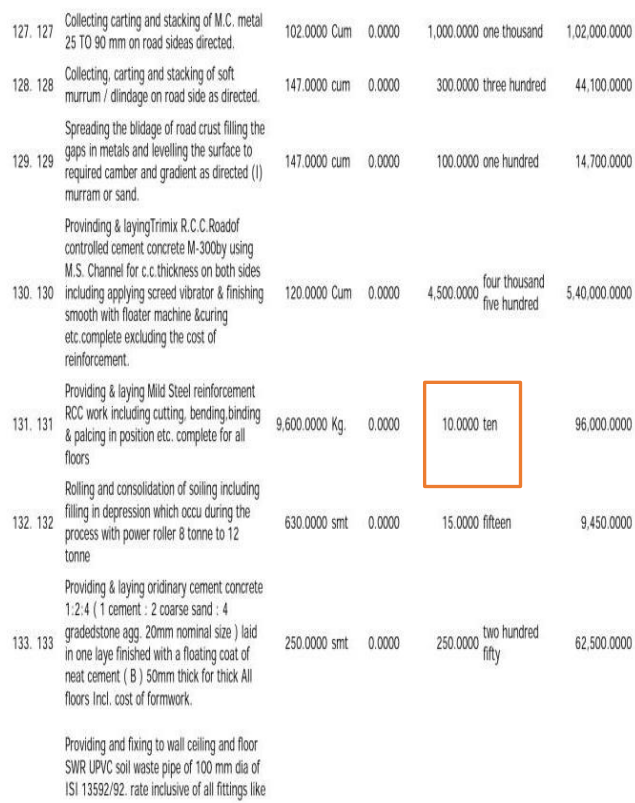

Fig. 1 (from the data obtained from contractor

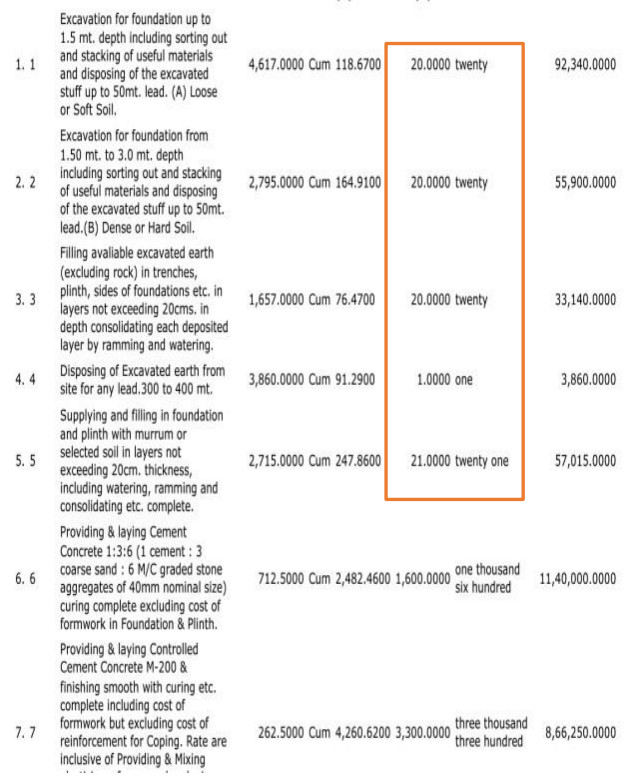

Fig. 2 (from the data obtained from contractor)

As shown in fig. 1, Contractor has quoted Rs. 10 per kg for mild steel. Practically it's not feasible to get the steel at this rate but contractor found that item to be remained saved (executed less than the mentioned) so he quoted less rates. Vice versa if contractor found some items to exceed than the estimated one than he may quote higher rate in the same.

As shown in Fig. 2, Contractor quoted extremely low rates in the mentioned items. Contractor has quoted just a single rupee in the item disposing of excavated earth from site lead up to 300 to $400 \mathrm{~m}$ while the SOR rate of the same item is Rs. 91.29. From the Contractors point of view, generally who excavate the soil he brings the earth at his own cost so it was not going to cost much. Tender is having such items like the disposing earth. Contractors uses that items to manage profit and minimizing tender amount and by doing so they make the tender unbalance.

\section{LITERATURE REVIEW}

\section{R\&B TENDER DOCUMENTS}

CLAUSE 1-A: Additional Security to be withheld for unbalanced rates: If the contractor has quoted unbalanced rates for items i.e. more or less than 10 (Ten) percent of the overall percentage of accepted tender, the payment of such items in the running bills will be made at estimated rate of that item plus or minus overall variation percentage of the accepted tender plus five percent of the estimated rate of that item. The balance amount as per accepted tender rate will be withheld from running bills and will be released on satisfactory completion of work in the final bill. No interest will be payable for such withheld amount. (R\&B D Circular No. PARACH/ 102008/ (61)C Dtd. 27-11-08 \& 03-05-13). [11] 
CLAUSE 14: As per the CLAUSE 14 of Roads and Buildings departments tender documents: Quantity of any item exceeds the $30 \%$ of the estimated quantity than upto $30 \%$ excess contractor is paid at the rate he quoted in the bid. And above 30\% contractor is paid as per SOR rates of the period during which the item first executed. Contractor may get the advantage here, he or she can quote the negligible rate in such items to make the tender lowest and after the award of contractor he or she enjoy the benefits of CLAUSE 14.

Bell (1989) proposed a single percentage factor method which is an alternative method to mitigate the unbalanced bidding in item rate contract which we now called as Percentage rate contract. It prevents quantity error exploitation in estimated quantities which is the main reason of unbalance bids and the same method can also prevent front-end loading of bid. [1]

Manzo (1997) found that unbalance bids negatively affects the contract amount. He found that after the changes in the quantities contract value increases than the bid amount. And also indicated that unbalanced bids increase the potential for disputes and litigation between the contractor and the owner. He also presented some lawsuits that involved unbalance bids. [9] [10]

Wang (2004) suggested an electronic based method for managing bid unbalancing in lump sum contracts. His method is based on the adjustment of the rates quoted by lowest bidder in estimated quantities and the rates quoted by all qualified bidders. But this changes don't affect the contractual price of the bidder. [13]

Catell D. W. et al. (2007) presented a critical assessment that finds flaws with all of the existing scientific proposals in unbalance bidding. And also finds fault with the technique that is incorporated into many of them by which prices are bounded by arbitrary upper and lower limits that have no scientific basis. [2]

Gransberg Douglas D. et al. (2009) reviewed the outcome of quantity estimation accuracy study of 462 transportation projects in Oklahoma, and finds that while evaluating the performance of a unit price (Item Rate) contract, the analyst should use absolute error rates than average error rates. 2. To reduce the mathematical unbalancing one should be accurate with the quantities mentioned in the estimate. This the best way to mitigate mathematical unbalancing. [4]

Heggstad et al. (2010) find unbalanced bidding as a corruption for collusive bid unbalancing. And mentioned unbalanced bidding as a fraud in government procurements. [5]

Yin et al. (2010) found that for contractor unbalanced bidding is a strategy to become the lowest bidder. But due to same practice owner get a low contract price and very high completion amount, which seriously affect the owner. Therefore, yin recommend that unbalanced bidding should be mitigated and strictly eliminated. [14]

Cattel D. W. et al. (2011) provided a framework to identify optimum item pricing, taking into account the effects of item prices on both the expected return that a contractor will enjoy and their risks. [3]

Renes (2012) proposed that unbalance bidding is due to quantity error exploitation. So he suggested to hide the quantities to mitigate the same problem. Renes suggested to mention the quantities as a range of number than the single value for all bid items. Renes also proposed a second method to control bid unbalancing by splitting the award between two or more successful bidders. But this alternative is not practical in construction field. [12] 
Hyari K. H. (2016) proposed a model based on approach for handling unbalanced bidding. This model provides a systematic procedure for rebalancing bid offers by adjusting the unit prices of all items submitted by every bidder based on the average unit price of all bidders in each item. The model still awards the project to the lowest qualified bidder. [6]

Hyari K. H. (2016) based on literature review suggested criteria for accepting unbalanced bids with the following three limitations: (1) none of the items should be priced below cost (2) unit prices submitted by the lowest bidder for any item are expected to be less than or equal to the average unit prices submitted by all bidders for that item; and (3) the bid is not materially unbalanced. [7]

Hyari K. H. et al. (2016) presented a detection model to help owners detect unbalanced bidding. The proposed model quantifies the risk by deviations of the actual quantities of work from the estimated quantities. The proposed model allows uncertainty in the quantities of work to be incorporated into the bid evaluation stage. [8]

\section{MAJOR FINDINGS}

- Government departments are facing the problem of unbalance bidding.

- Quantity error exploitation and Front end loading are the most commonly found for the unbalance tender.

- Mitigation of front end loaded tender is done by R\&B department of Gujarat government by providing clause1 $\mathrm{A}$.

- Unbalance tender keep the contract price lower but increases the final amount. It also increases the profit of contractor.

- Unbalance bidding is fraud practice and include corruption.

- Unbalance tender challenges the economic stability of project.

- Unbalance tender increase the potential for dispute between contractor and owner.

- To mitigate the quantity error exploitation various authors have proposed different model.

- Renes (2012) suggested to hide quantities to mitigate Quantity error exploitation.

\section{CONCLUSION}

If we look at the Government sector of Gujarat, R\&B department had found out the practice of unbalance bidding and also taken steps to control unbalance bidding (Front end loading) by providing clause $1 \mathrm{~A}$. From the literature review we can say quantity error exploitation $\&$ collusive bidding is still a major issue to be mitigated. From the review of Renes (2012) about hiding quantities Unit Quantity Contract came into mind.

Unit Quantity Contract: It will be like Item Rate Contract but in the same contract, contractor will be provided just a unit (1unit) quantity for all line items. Contractor has to quote a rate for all items and submit the bid. Afterwards it will be multiplied with estimated quantities by owner and from the total amount lowest bidder will be found out.

During E-tendering quantities can be uploaded during bidding stage and make it invisible for contractor so there will be no chance of manipulation of quantities after the bidding. 
There are chances of collusion between estimator and contractor. So estimating department should be most secure and data should remain confidential as well government should appoint such estimator or agencies which are not involved with other divisions of department and contractors.

\section{SAME HYPOTHETICAL EXAMPLE:}

\begin{tabular}{|c|c|c|c|c|}
\hline Item & Quantity & SOR & Contractor 1 & Total \\
\hline $\begin{array}{c}\text { Brick } \\
\text { Masonary }\end{array}$ & $1 \mathrm{~m}^{3}$ & 3500 & & \\
\hline Plaster & $1 \mathrm{~m}^{2}$ & 150 & & \\
\hline
\end{tabular}

By applying unit quantity contract, contractor will not be having quantities so he/she won't get idea about change in quantities and he will not quote the rate in unbalance manner. By doing so the major issue of quantity error exploitation can be mitigated.

If we consider the fig. 1 , if contractor had not given the quantity of mild steel than he would have quoted at least the price of mild steel Rs.30-35 than the Rs.10. Same is the case with fig. 2 if the quantities were 1 unit than contractor would have thought before quoting this much unbalance rates.

Here people argue that contractor quotes the rates as per the mentioned quantities means if there is a large quantity contractor can do the same work in lesser rates than the small quantity item. To resolve the same issue contractor should be given drawings of the building. From the drawings contractor can get rough idea about the quantity to be executed and can quote the rates accordingly.

\section{REFERENCES}

[1] Bell, M. (1989). "Unbalanced bidding in government contracts." Ph.D. thesis, George Washington Univ., Faculty of the National Law Center, Washington, DC.

[2] Cattell D. W., Bowen P. A., and Kaka A. P., "Review of Unbalanced Bidding Models in Construction," JOURNAL OF CONSTRUCTION ENGINEERING AND MANAGEMENT @ A ASCE / AUGUST 2007.

[3] Cattell D. W., Bowen P. A., and Kaka A. P., "Proposed Framework for Applying Cumulative Prospect Theory to an Unbalanced Bidding Model," JOURNAL OF CONSTRUCTION ENGINEERING AND MANAGEMENT @ ASCE, 2011.

[4] Gransberg D. D. and Riemer C., "Impact of Inaccurate Engineer's Estimated Quantities on Unit Price Contracts," JOURNAL OF CONSTRUCTION ENGINEERING AND MANAGEMENT @ ASCE / NOVEMBER 2009.

[5] Heggstad, K., Frøystad,M., and Isaksen, J. (2010). "The basics of integrity in procurement: A guidebook." Chr. Michelsen Institute, Bergen, Norway.

[6] Hyari K. H., "Handling Unbalanced Bidding in Construction Projects: Prevention Rather Than Detection " J. Constr. Eng. Manage., 2016, 142(2): 04015060, 2015.

[7] Hyari K. H., "The Controversy around Unbalanced Bidding in Construction: Seeking a Fair Balance," J. Prof. Issues Eng. Educ. Pract., 04016015, 2016.

[8] Hyari K. H., Tarawneh Z. S., and Katkhuda H. N., "Detection Model for Unbalanced Pricing in Construction Projects: A Risk-Based Approach," J. Constr. Eng. Manage., 04016078, 2016.

[9] Manzo, F. (1997). "The impact of an unbalanced bid on the change order process." GREYHAWK North America, LLC, Mount Laurel, NJ.

[10] Manzo, F., and Tell, S. (1997). "Unbalanced bids and avoiding disputes relating to them." GREYHAWK, New York.

[11]ROADS AND BUILDINGS DEPARTMENT GUJARAT TENDER DOCUMENTS

[12]Renes, (2012). "Fighting skewed bids in the EU, A comparative analysis." Erasmus School of Law, Rotterdam, Netherlands.

[13] Wang W.-C., "Electronic-Based Procedure for Managing Unbalanced Bids," JOURNAL OF CONSTRUCTION ENGINEERING AND MANAGEMENT @ ASCE/MAY/JUNE 20042004.

[14] Yin, Y., Qiao, L., and Li, B. (2010). "Research on the owner's tactics to unbalanced bid under the mode of code of valuation with bill quantity of construction works." Proc., Industrial Engineering and Engineering Management (IE\&EM), 2010 IEEE 17th Int. Conf., IEEE, Piscataway, NJ, 249-252. 